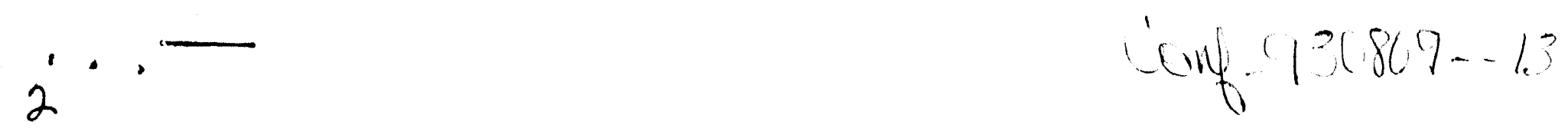

\title{
PRODUCTION AND TESTING OF THE VITAMIN B6 FINE-GROUP AND THE \\ BUGLE-93 BROAD-GROUP NEUTRON/PHOTON CROSS-SECTION LIBRARIES DERIVED FROM ENDF/B-VI NUCLEAR DATA*
}

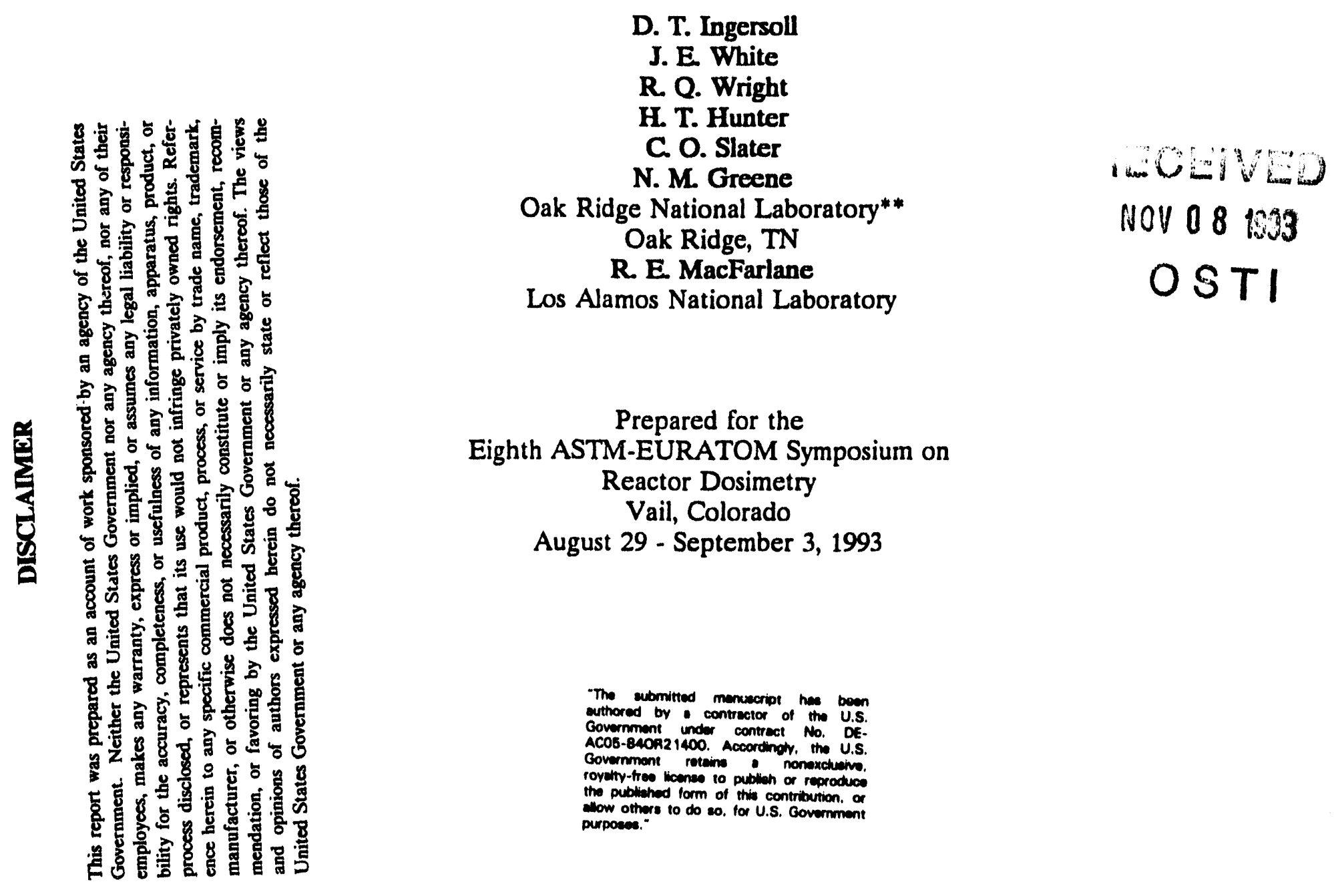

*Research sponsored by the U.S. Nuclear Regulatory Commission.

**Managed by Martin Marietta Energy Systems, Inc. for the U.S. Department of Energy, under Contract DE-AC05-84OR21400. 
Daniel T. Ingersoll, 1 John E. White, 2 Richard Q. Wright, ${ }^{3}$ Hamilton $T$. Hunter, ' Charles O. Slater, 'Robert E. MacFarlane, ${ }^{4}$ and Norman M. Greene 3

PRODUCTION AND TESTING OF THE VITAMIN-B6 FINE-GROUP AND THE BUGLE-93 BROAD-GROUP NEUTRON/PBOTON CROSS-SECTION IIBRARIES DERIVED FROM ENDF/BVI NUCLEAR DATA

REFERENCE: Ingersoll, D. T., White, J. E., Write, R. Q., Hunter, H. T., slater, C. O., MacFarlane, R. E., and Greene, N. M., "Production and Testing of the Vitamin-B6 Fine-Group and the Bugle-93 Broad-Group Neutron/Photon Cross-section Libraries Derived from ENDF/B-VI Nuclear Data," Reactor Dosimetry ASTM STP 1228, Harry Farrar IV, E. Parvin Lippincott, and John G. Williams, Eds., American Society for Testing and Materials, Philadelphia, 1994.

ABSTRACT: A new multigroup cross-section library based on ENDF/B-VI data has been produced and tested for light water reactor shielding and reactor pressure vessel dosimetry applications. The broad-group library is designated BUGLE-93. The processing methodology is consistent with ANSI/ANS 6.1.2, since the ENDF data were first processed into a fine-group, "pseudo problem-independent" format and then collapsed into the final broad-group format. The fine-group library is designated VITAMIN-B6. An extensive integral data testing effort was also performed. In general, results using the new data show significant improvements relative to earlier ENDF data.

REYWORDs: Nuclear data, cross sections, pressure vessel dosimetry, reactor shielding

The generation of multigroup cross-section libraries with broad energy group structures is primarily for reasons of economy. Despite the impressive performance of modern computers, it is stili often impractical to perform two-and three-dimensional radiation transport analyses using pointwise data or finely structured multigroup data. Even for one-dimensional analyses, it is often more efficient to use few-group data to perform the initial scoping analysis, and then advance

'section Head and research staff, respectively, Nuclear Analysis and Shielding Section, Engineering Physics and Mathematics Division, Oak Ridge National Laboratory, Oak Ridge, TN 37831-6363.

${ }^{2}$ Research staff, Engineering Physics Information Center (EPIC), Engineering Physics and Mathematics Division, Oak Ridge National Laboratory, Oak Ridge, TN 37831-6362.

${ }^{3}$ Research staff, Computing Applications Division, Oak Ridge National Laboratory, Oak Ridge, TN 37831-6370.

${ }^{4}$ Research staff, Los Alamos National Laboratory, Los Alamos, NM 87545 . 
to finer group data as accuracy requirements are increased. The establishment of reference broad-group libraries is desirable in order to avoid duplication of effort, both in terms of the library generation and verification, and to assure a common data base for comparisons among program perticipants.

A new multigroup cross-section library based on ENDF/B-VI data has been produced and tested for light water reactor shielding and reactor pressure vessel dosimetry applications. The broad-group library, which is designated BUGLE-93, is intended to replace the aging BUGLE-80 and SAILOR Iibraries. The ENDF data were first processed into a fine-group, "pseudo problem-independent" format using the NJOY processing system and then collapsed into the final broad-group format using the AMPX code system. The fine-group library is designated VITAMIN-B 6 and is modeled after the earlier VITAMIN-C and VITAMIN-E libraries. Both the BUGLE-93 and the VITAMIN-B6 libraries are available in a format for direct use in radiation transport codes such as ANISN, DORT, TORT, MORSE, and other similar multigroup codes. It 1 s expected that the general naicure of the libraries, especially the fine-group library, will make the data useful for other shielding applications and reactor physics analyses.

\section{BACKGROUND}

Shortly after the release of Vergion 4 of the Evaluated Nuclear Data Files (ENDF/B-IV) in 1974[1], the ANS 6.1 working Group began working to develop a standardized approach for generating multigroup cross sections to be used in radiation protection and shielding analyses for nuclear power plants. Their recommended methodology, which is detailed in ANSI/ANS $6.1 .2[2]$, consists of a two stage process: (1) the processing of ENDF files into a fine-group, "pseudo problem-independent" library, followed by (2) the collapsing of the fine-group library into the desired broad-group, problem-dependent library. The library generated in the first stage is considered "pseudo problem-independent" if it has been prepared with enough detail in energy, temperatures, and resonance self-shielding so as to be applicable to a wide range of epecific problems. The problem-dependent library is then derived from the fine-group library by applying temperature and resonance self-shielding information and collapsing to a smaller number of groups.

The activities of the ANS 6.1 .2 Working Group motivated the development and generation of a broad-group library, designated BUGLE, specifically tailored for power reactor radiation shielding analyses. However, initial experience with the BUGLE library indicated specific deficiencies; hence, a subsequent library was produced with modified specifications and designated as BUGLE-80[3]. In parallel to the BUGLE-80 effort was an independent project to analyze fluence levels at the pressure vessel location in epecific light-water power reactors. This project culminated in the production of a broad-group cross-section library, designated SAILOR[4], which shares many of the same specifications as the BUGLE-80 library but uses additional problem-dependent weighting spectra. Both of these libraries, derived from ENDF/B-IV, have been used extensively in the LWR shielding community, but are now in need of updating with more modern and accurate nuclear data.

Version 6 of ENDF was released for open distribution in 1990 after an extensive measurement and evaluation effort spanning nearly 10 years[ $[\underline{5}]$. Seventy-four of the 320 evaluations contained in the library are new for Version 6 . Most of the new evaluations represent relatively important nuclides throughout the mass range and many of them include substantial changes to the cross-section data. In addition to incorporating improved experimental data and model predictions, several 
format changes were made to provide for better representation of the underlying physics and the extension to higher energies.

Of special interest for LWR shielding analyses are improvements to the iron evall -ion. For more than a decade, it had been widely observed in integral benchmark experiments that neutron transmission through thick iron was consistently underpredicted in the energy range of 3 to $10 \mathrm{MeV}$. It became apparent that at least a portion of the discrepancieg were due to the continuum inelastic scattering cross section for ${ }^{57} \mathrm{Fe}$. The incorporation of new nuclear data for iron and improved formats for ENDF/B-VI provide a more accurate representation of this important cross section. As a consequence, the new iron data show oignificant improvements in the calculated-to-experiment ratios for several key benchmarks, including in-reactor dosimetry benchmarks.

Because of these observations and other known improvements contained in ENDF/B-VI, it became clear that use of these data will substantially benefit light-water reactor shielding applications.

\section{CROSS-SECTION PROCESSING}

The calculational approach used to produce a new ENDF/B-VI library is consistent with the ANS 6.1 .2 standard. Specifically, the ENDF data were first processed into a fine-group set similar to the ENDF/B-IV-based VITAMIN-C Iibrary ( 6 ) and the ENDF/B-V-based VITAMIN-E library [7] and then collapsed into a broad-group set similar to BUGLE-80. While the overall methodology is the same, a different system of processing codes was used to perform the initial phase of the processing. The earlier VITAMIN-C and VITAMIN-E libraries were created from ENDF files using a combination of the AMPX code system [ 8 ] and the MINX code[9]. However, these codes were not kept current with the format changes in ENDF/B-VI and it was prohibitively expensive to make the required changes to the codes for this project. Instead, a hybrid approach was taken employing both the NJOY91 modular code system(10) and the AMPX77 code system(11).

Several modules of NJOY91 were used to process the neutron interaction, gamma-ray production, and gamma-ray interaction data from the ENDF/B-VI formats to a group-averaged format. The SMILER module in the AMPX77 code system was then used to translate the intermediate NJOY91 file into the AMPX master format for the fine-group library. Additional modules from the AMPX77 system were then used to perform the computations and manipulations needed to produce the final broad-group library.

In developing the detailed specificat lons of the fine-group and broad-group libraries $(12)$, considerable priority was given to backward compatibility with the older libraries, especially BUGLE-80. Improvements were made, where possible, based on our substantial experience from past library production efforts and experience from the user community.

\section{FINE-GROUP IIBRARY SPECIFICATIONS}

The fine-groun "pseudo problem-independent" library is designated as VITAMIN-B6, indicating its ancestry from the earlier VITAMIN-C and VITAMIN-E libraries. The initial set of materials processed for VITAMIN-B6 contain nearly 120 nuclides, including all nuclides contained in the original BUGLE-80 library (Table 1). Also indicated in Table 1 are those nuclide evaluations which are "new" for ENDF/B-VI, i.e. they contain major revisions to the nuclear data. 
TABLE 1. ENDE/B-VI nuclides processed for the VITAMIN-B6 and the BUGLE-93 libraries.

\begin{tabular}{|c|c|c|c|c|c|c|c|c|c|c|c|}
\hline$z$ & Nuclide & $\begin{array}{l}\text { New } \\
\text { Eval. }\end{array}$ & $\begin{array}{c}\text { BUGLE- } \\
80\end{array}$ & $z$ & Nuclide & $\begin{array}{l}\text { New } \\
\text { Eval. }\end{array}$ & $\begin{array}{c}\text { BUGLE- } \\
80\end{array}$ & $z$ & Nuclide & $\begin{array}{l}\text { New } \\
\text { Eval. }\end{array}$ & $\begin{array}{l}\text { BUGLE- } \\
80\end{array}$ \\
\hline & $\mathrm{H}-1(\mathrm{H} 2 \mathrm{O})$ & $\mathrm{x}$ & $x$ & 28 & $\mathrm{Ni}-58$ & $x$ & - & 79 & $A u-197$ & $x$ & \\
\hline & $\mathrm{H}-1(\mathrm{CH} 2)$ & $x$ & & & $\mathrm{Ni}-60$ & $x$ & - & 82 & $\mathrm{~Pb}-206$ & $x$ & $"$ \\
\hline & $\mathrm{H}-2(\mathrm{D} 2 \mathrm{O})$ & $x$ & & & $\mathrm{Ni}-61$ & $x$ & * & & $\mathrm{Pb}-207$ & $x$ & • \\
\hline & $\mathrm{H}-3$ & $x$ & $x$ & & $\mathrm{~N} 1-62$ & $x$ & - & & $\mathrm{Pb}-208$ & $x$ & * \\
\hline & $\mathrm{He}-3$ & $x$ & & & $\mathrm{Ni}-64$ & $x$ & * & 83 & $\mathrm{Bi}-209$ & $x$ & \\
\hline & $\mathrm{He}-4$ & & $x$ & 29 & $\mathrm{Cu}-63$ & $x$ & • & 90 & Th-230 & & \\
\hline 3 & LI-6 & $x$ & $x$ & & Cu-65 & $x$ & * & & Th-232 & & $x$ \\
\hline & LL-7 & $x$ & $x$ & 31 & $\mathrm{Ga}$ & & & 91 & $\mathrm{~Pa}-231$ & & \\
\hline 4 & Be-9 & $x$ & $x$ & 39 & $Y-89$ & $x$ & & & $\mathrm{~Pa}-233$ & & \\
\hline & Be-9 (Therm) & $x$ & & 40 & $2 r$ & & $x$ & 92 & $U-232$ & & \\
\hline 5 & B-10 & $x$ & $x$ & 41 & $\mathrm{Nb}-93$ & $x$ & $x$ & & U-233 & & $x$ \\
\hline & B-11 & $x$ & $x$ & 42 & Mo & & $x$ & & $U-234$ & & $x$ \\
\hline 6 & C & $x$ & $x$ & 45 & $R h-103$ & & & & U-235 & $x$ & $x$ \\
\hline & C (Graphite) & $x$ & & 47 & Ag-107 & & $x$ & & $U-236$ & $x$ & $x$ \\
\hline 7 & $\mathrm{~N}-14$ & $x$ & $x$ & & Ag-109 & & $x$ & & U-237 & & \\
\hline & $\mathrm{N}-15$ & & & 48 & $\mathrm{Cd}$ & & $x$ & & $U-238$ & $x$ & $x$ \\
\hline 8 & $0-16$ & $x$ & $x$ & 49 & $\ln$ & $x$ & & 93 & $\mathrm{~Np}-237$ & & \\
\hline & $0-17$ & & & 50 & Sn & & $x$ & & $\mathrm{~Np}-238$ & & \\
\hline 9 & $F-19$ & $x$ & $x$ & 56 & $\mathrm{Ba}-138$ & & $x$ & & $N p-239$ & $x$ & \\
\hline 11 & $\mathrm{Na}-23$ & & $x$ & 63 & Eu-151 & $x$ & $x$ & 94 & Pu-236 & & \\
\hline 12 & $\mathrm{Mg}$ & & $x$ & & Eu-152 & $x$ & & & Pu-237 & & \\
\hline 13 & Al-27 & & $x$ & & Eu-153 & $x$ & $x$ & & Pu-238 & & $x$ \\
\hline 14 & Si & & $x$ & & Eu-154 & $x$ & & & Pu-239 & $x$ & $x$ \\
\hline 15 & P-31 & & $x$ & & Eu-155 & $x$ & & & Pu-240 & $x$ & $x$ \\
\hline 16 & 5 & & $x$ & 72 & & & & & Pu-241 & $x$ & $\begin{array}{l}x \\
x\end{array}$ \\
\hline & $5-32$ & & & & $H f-174$ & & & & Pu-242 & & $x$ \\
\hline 17 & $\mathrm{Cl}$ & & $x$ & & $\mathrm{Hf}-176$ & & & & Pu-243 & & \\
\hline 19 & $K$ & & $x$ & & $H f-177$ & & & & Pu-244 & & \\
\hline 20 & $\mathrm{Ca}$ & & $x$ & & $H f-178$ & & & 95 & $A m \cdot 241$ & $x$ & $x$ \\
\hline 22 & $\mathrm{Ti}$ & & $\mathrm{x}$ & & $H f-179$ & & & & $A m-242$ & & \\
\hline 23 & V & $x$ & $x$ & & $H f-180$ & & & & $A m-242 m$ & & \\
\hline 24 & Cr-50 & $x$ & - & 73 & Ta-181 & & $x$ & & $A m-243$ & $x$ & \\
\hline & $\mathrm{Cr}-52$ & $x$ & * & & Ta-182 & & & 96 & $\mathrm{Cm}-241$ & & \\
\hline & $\mathrm{Cr}-53$ & $x$ & * & 74 & $w$ & & & & $\mathrm{Cm}-242$ & & \\
\hline & Cr-54 & $x$ & * & & $W-182$ & & $x$ & & $\mathrm{Crn}-243$ & & \\
\hline 25 & $M n-55$ & $x$ & $x$ & & W-183 & & $x$ & & $C_{1 n}-244$ & & \\
\hline 26 & $F_{\theta-54}$ & $x$ & • & & W-184 & & $x$ & & $\mathrm{Cm}-245$ & & \\
\hline & Fe-56 & $x$ & * & & $W-186$ & & $x$ & & $\mathrm{Cm}-246$ & & \\
\hline & Fo.57 & $x$ & " & 75 & $R \theta-185$ & $x$ & & & $\mathrm{C} \cdot \mathrm{m}-247$ & & \\
\hline & $F_{\theta-58}$ & $x$ & $\star$ & & $R \theta-187$ & $x$ & & & $\mathrm{Cm}-248$ & & \\
\hline 27 & Co-59 & $x$ & $x$ & & & & & & & & \\
\hline
\end{tabular}

* Only the elemental data for $\mathrm{Cr}, \mathrm{Fe}, \mathrm{Ni}, \mathrm{Cu}$, and $\mathrm{Pb}$ are contained in BUGLE-80 
The Bondarenko ( $f$-factor) method is used for handling resonance self-shielding and temperature effecta. All materials were processed at temperatures of $300,600,1000$, and $2100 \mathrm{~K}$ and most materials were processed with 6 to 8 values of the background cross section, $\sigma_{0}$. The thermal scattering law data for graphite, polyethylene, beryllium metal, heavy water, and light water were processed at all temperatures available on the ENDF tape.

Feedback from users of previous VITAMIN librarieg, which were developed primarily for "fast" neutron applications, indicated that the neutron energy group structure appears adequate at higher energies, but that refining the neutron group atructure in the thermal energy range would greatly expand the usefulness of the fine-group library for a broader range of applications. On the other hand, experience with a 27-neutron-group library from the sCALE system[13], which was developed primarily for criticality safety and shielding analyses for out-of-core applications, has been very favorable in terms of the number of thermal energy groups, but lacks adequate resolution in the high energy range. Hence, the VITAMIN-B6 neutron energy group structure was constructed as a compromise and improvement over the VITAMIN-E and SCALE IIbraries. The resulting structure includes 199 neutron energy groups, 36 of which are in the thermal energy range (below $5.043 \mathrm{eV}$ ), and 42 gamma-ray energy groups. By combining the best features of the VITAMIN and 27-group neutron energy grids, we have maximized our options for creating the best problem-independent energy grid for a variety of reactor designs including thermal (water- or graphite-moderated) and fast reactor systems. Consequently, problem-dependent libraries can be easily derived from VITAMIN-B6 without having to repeat the multigroup averaging for different group structures.

The neutron weighting function for VITAMIN-B6 consists of a smoothly varying combination of a Maxwellian thermal opectrum, a fission spectrum, and a "1/E" slowing down spectrum. The breakpoint energy between the Maxwellian and $1 / E$ segments is $0.125 \mathrm{eV}$ and the breakpoint energy between the $1 / \mathrm{E}$ and the flssion segments $1 \mathrm{~s} 820.8 \mathrm{keV}$. The fission temperature has been adfusted to better reflect the neutron spectrum in a thermal reactor $(\theta=1.273 \mathrm{MeV})$. The use of a large number of energy groups should make the exact functional form and energy break points less important compared to generating a broad-group library directly from ENDF data. The photon weighting spectrum consists of a 1/E epectrum with a "roll-off" of the spectrum at lower and higher energiea.

The order of scattering used for both nfutrons and photons $18 P_{7}$ for nuclides up through $Z=30$ (zinc) and $P_{5}$ for the remainder of the nuclidea. Most calculations are likely to be done with $P_{3}$ scattering, but for some problems, e.g., when alngle scatter events dominate, a higher order may be required.

\section{BROAD-GROUP IIBRARY SPECIFICATIONS}

The problem-dependent broad-group cross section library derived from VITAMIN-B6 is designated as BUGLE-93. The name was chosen to be consistent with the earlier BUGLE libraries and indicates its year of initial release. BUGLE-93 contains all nuclides available in the VITAMIN-B6 library (Table 1). Both the neutron and the gamma-ray group atructures are ldentical with the previcusly developed BUGLE-80 ilbrary, which includes 47 neutron groups and 20 gamma-ray groups.

BUGLE-93 was produced by collapsing the VITAMIN-B6 fine-group library with the same methodology and reactor models used for both BUGLE-80 and SAILOR. Five separate sets of broad-group cross sections were generated. First, all nuclides in VITAMIN-B6 were collapsed to 47 
neutron groups and 20 gamma-ray groups using a weighting spectrun based on the flux in the concrete shield of a PWR model. This corresponds to the BUGLE-80 welghting function. Also, selected materials were resonance oelf-ahielded, corrected for temperature effecta, and collapsed using flux spectra computed for a BWR fuel cell, a PWR fuel cell, a seel-water mixture, and a PWR pressure vessel. These sets correspond to the SAILOR weighting functions. The characteristics of BUGLE-93 were deliberately kept as similar as possible to the BUGLE-80 and SAILOR libraries in order to facilitate the rapid implementation of BUGLE-93 data into the LWR community.

The resulting broad-group library is available in ANISN format. As with the BUGLE-80 and SAILOR libraries, BUGLE-93 contains several response functions, including neutron and photon kerma, common dosimetry reactions, and dose responses.

\section{DATA TESTING}

Because of the complexity of processing evaluated nuclear data into the multigroup formats used by the applications codes, it is important that the cross-gection libraries be tested in their final format using accepted integral benchmarks. The amount of effort, however, can be extensive due to the vast number of nuclear interactions which comprise the crose sections and due to the broad range of ahielding applications. The integral testing effort is then forced to be a compromise between thoroughness and affordability. The integral testing serves not only to identify data processing mistakes, but also help to assess the potential impact of the new cross sectlons for apecific applications.

In addition to using automated checking routines to verify certain aspects of the data flies, numerous integral benchmarks were analyzed using the new cross sections. These included thermal reactor, fast reactor, and shielding benchmarks. Most of the benchmarks are part of the set of CSEWG benchmarks which have been epeciflcally reviewed and approved as valid for data testing(14). Other benchmarks were also included when considerable experience with the data already existed. More than 40 total benchmarks were selected to test the VITAMIN-B6/BUGLE-93 libraries. Highlighte from fust a few benchmarks are given below.

It should be noted that the results presented below are preliminary. Production of a cross-section library requires numerous iterations between data processing and testing, with numerous processing code flxes occurring between iterations. The results avaliable at the time that this paper was prepared are based on calculations using cross aections from an early processing lteration. However, the processing changes whlch were made in later 1terations are not expected to igniflcantly impact the conclusions from these comparisons.

The "I-series" thermal reactor benchmarks consist of a series of ${ }^{235_{U}}$ (as uranyl fluoride) reflected and unreflected spheres in water. These benchmarks were analyzed using a fine-group, ENDF/B-V-based thermal reactor library from the sCALE syetem, designated LAW-238(15), and the VITAMIN-B6 library. The calculated $k_{\text {off }}$ as a function of leakage from the opheres are compared in igure 1. It can be een that the VITAMIN-B6 data $y$ leld a 0.6 percent lower $k_{\text {efr }}$ which is a ignificant improvement in all cases. Moreover, the slight trend in $k_{\text {off }}$ with leakage observed for ENDF/B-VI data is only about half of that seen for ENDE/B-V data.

Another serles of thermal reactor benchmarks, designated the "BAPL-Beriea", consist of water-moderated uranium oxide critlcal 


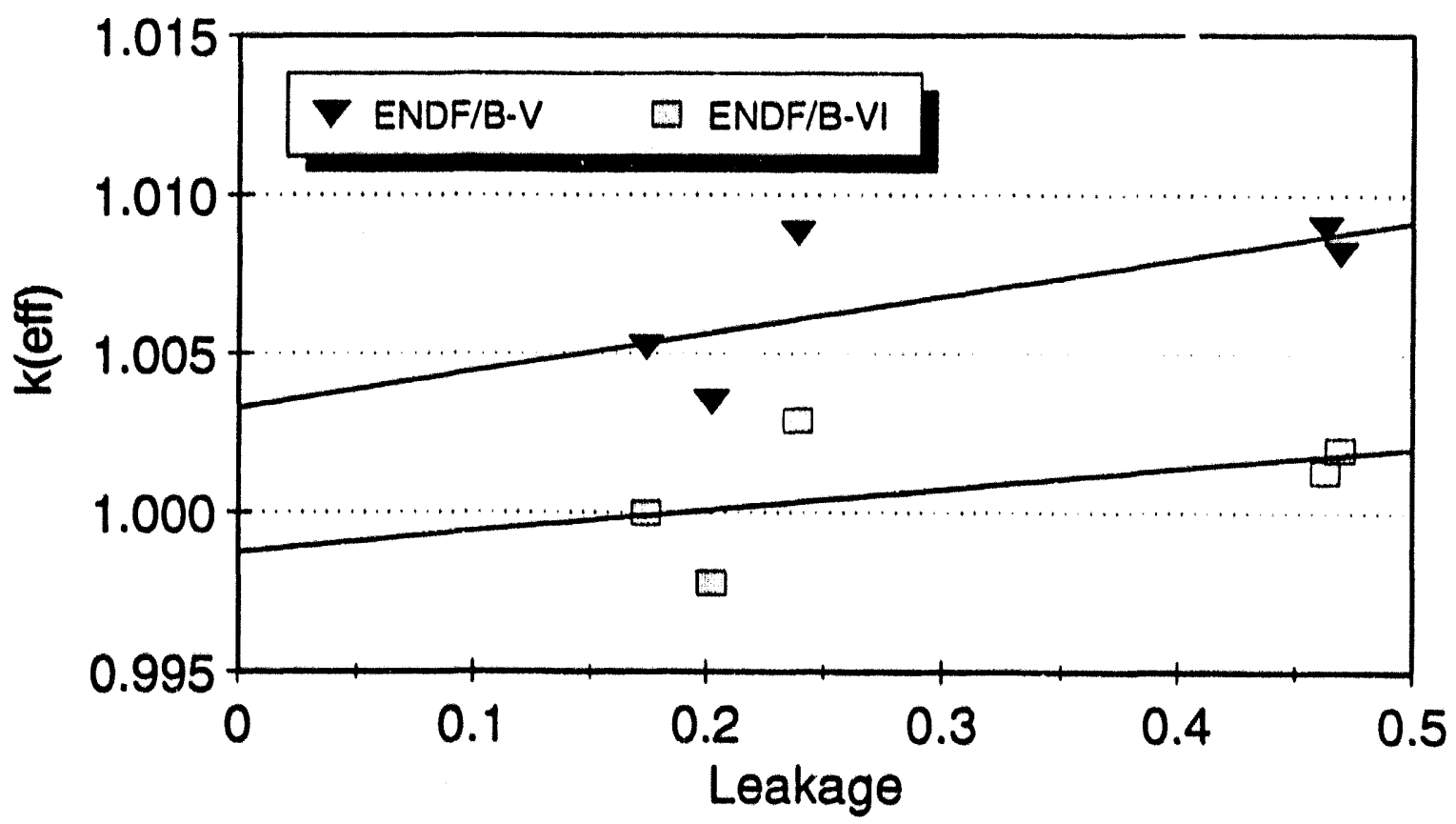

EIGURE 1. Comparison of $k_{\text {eff }}$ as a function of leakage for the L-series thermal reactor benchmarks.

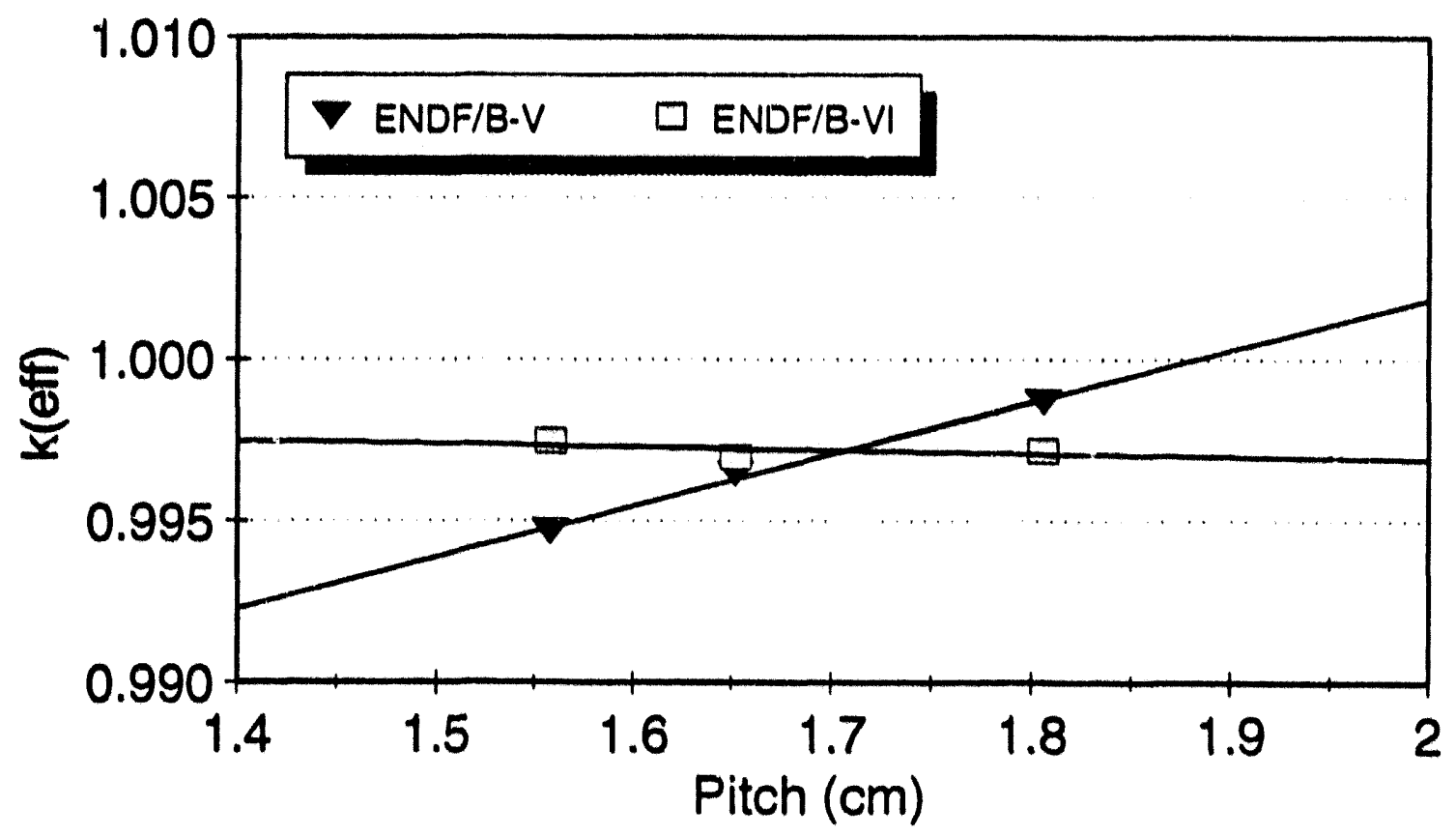

EIGURE 2. Comparison of $k_{\text {eff }}$ as a function of lattice pitch for the BAPL-series thermal reactor benchmarks. 
lattices in a triangular pattern. Comparisone of the VITAMIN-B6 and SCALE LAW-238 data are shown in Figure 2, which plots $k_{\text {eff }}$ a a function of lattice pitch. The noticeable trend with pitch which was observed for ENDF/B-V is nearly eliminated with ENDF/B-VI data. The particular changes to the croes sections that are reaponsible for this improvement have not yet been leolated, but are probably a combined effect of 160 , ${ }^{235_{\mathrm{U}}}$ and ${ }^{238_{\mathrm{U}}}$ data improvements.

Because of the Importance of iron In LWR pressure veseel and reactor cavity dowimetry and due to the impact of the new Iron evaluation, opecial emphasie was given to analyzing ohielding benchmarks containing abetantial amounts of iron. One weh pair of benchmarks is the Illinole Iron ephere benchmarks, which conglet of a 30.5-cm-thick spherical hell of iron surrounding elther a ${ }^{252} \mathrm{Cf}$ epontaneous fiesion source or a D-T fuvion vource(16). Meawurements of the fast neutron leakage from the phere are hown in Flgures 3 and 4 compared to leakages predicted using VITAMIN-B6 and VITAMIN-E (BNDE/B-V). Although both data ets continue to underpredict the measurements below 3 MeV, the now Version 6 data yield a eubstantial improvement in the agreement above $3 \mathrm{MeV}$.

\section{CONCLUSIONE}

The avallablilty of the now crose-section librarles ehould be of -ignifleant value to the IWR shielding community. The improved data will provide for more complete and accurate ohielding analyses, ultimately reducing design biases and design uncertainties. The VITAMIN-B6 library w11l have general value to a broad range of current and Euture applicatione, while the BUCLE-93 11 brary will be of direct and immediate importance to exleting preseure veseel eurvelliance programe and for plant iffe extension etudies.

\section{ACRONOWEDOEMENYS}

The authore are indebted to neveral contributore for many of the technlcal detali. Included in this report. For the current work, we wish to acknowledge our Indebtednees to $R$. W. Rousein for his guldance on the development of epeciflcatione for the libraries and his coneultation throughout the project. Also, we are grateful to professor Mark Williams of Loulelana state University for the benefit of his Insight and data testing experience.

\section{REPGRNCES}

(1) "ENDF/B-IV summary Documentation," BNL-NCs-17541 (ENDE-201) 2nd Edition (October 1975 ).

(2) "Noutron and Camina-Ray Crose sectlone for Nuclear Radiation Protection Calculation for Nuclear Power Plants," ANSI/ANS-6.1.2-1983 (Auguet 1983) and Revision 1989 (Reafflrmed).

(3) "BUCLE-80, Coupled 47 Neutron, 20 Oamma-Ray, P3, Crose-section Library for IWR shlelding Calculatione," RSIC Data Library Collection, DLC-075 (1980).

(4) "SAILOR: Coupled, Self-shlolded, 47-Noutron, 20 Gamma-Ray, P3, Crosi-section Library for Light Water Ractors, $\pi$ RS.TC Data Library Collection DLC-076 (1985).

(5) P. F. Rove, "ENDE/B-VI summary Documentation," BNL-NCs-17541

(ENDE-201) 4th Edition (October 1991). 


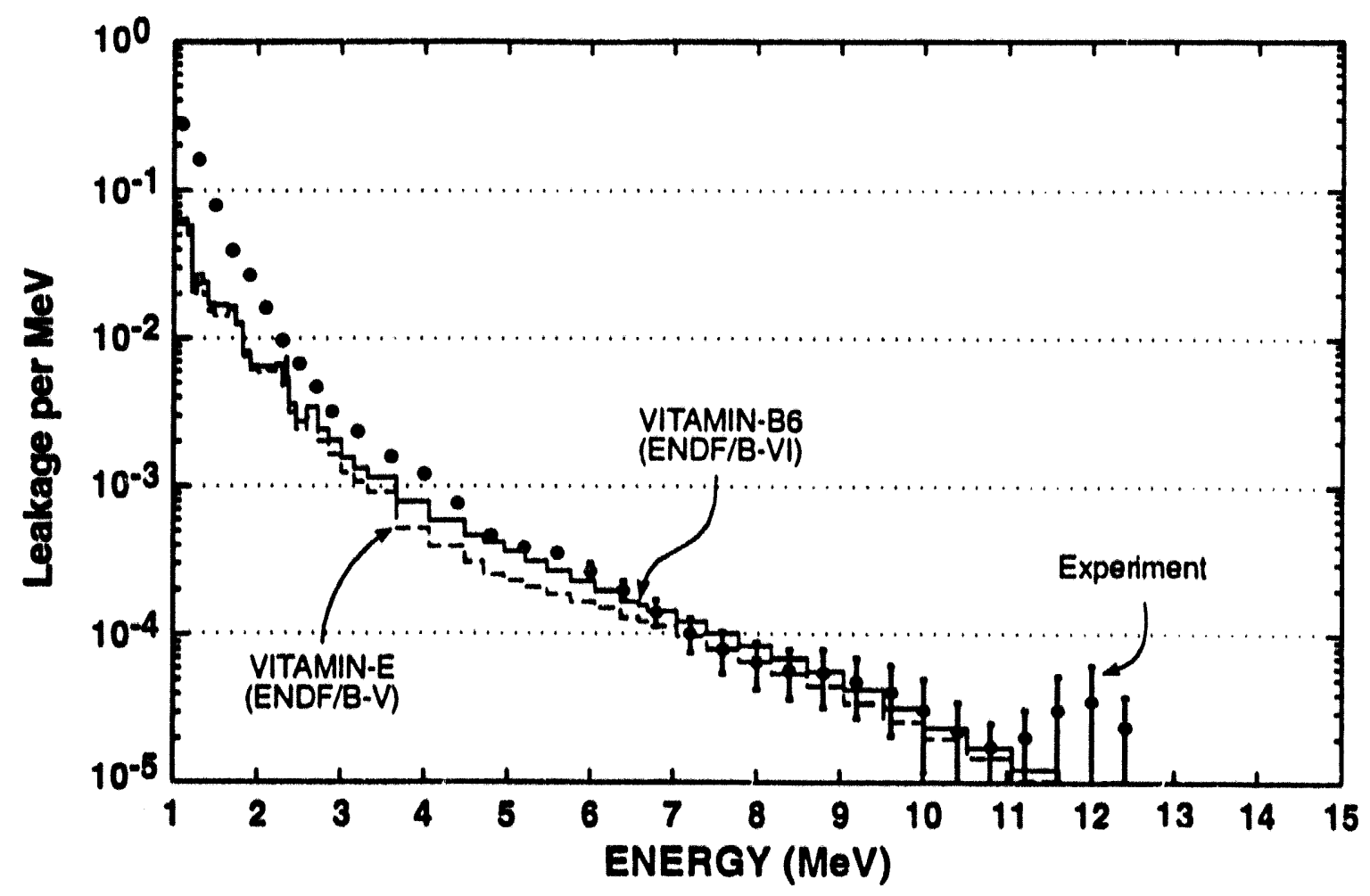

FIGURE 3. Comparison of leakage spectrum from Illinois iron sphere with ${ }^{252} \mathrm{Cf}$ fission source at its center.

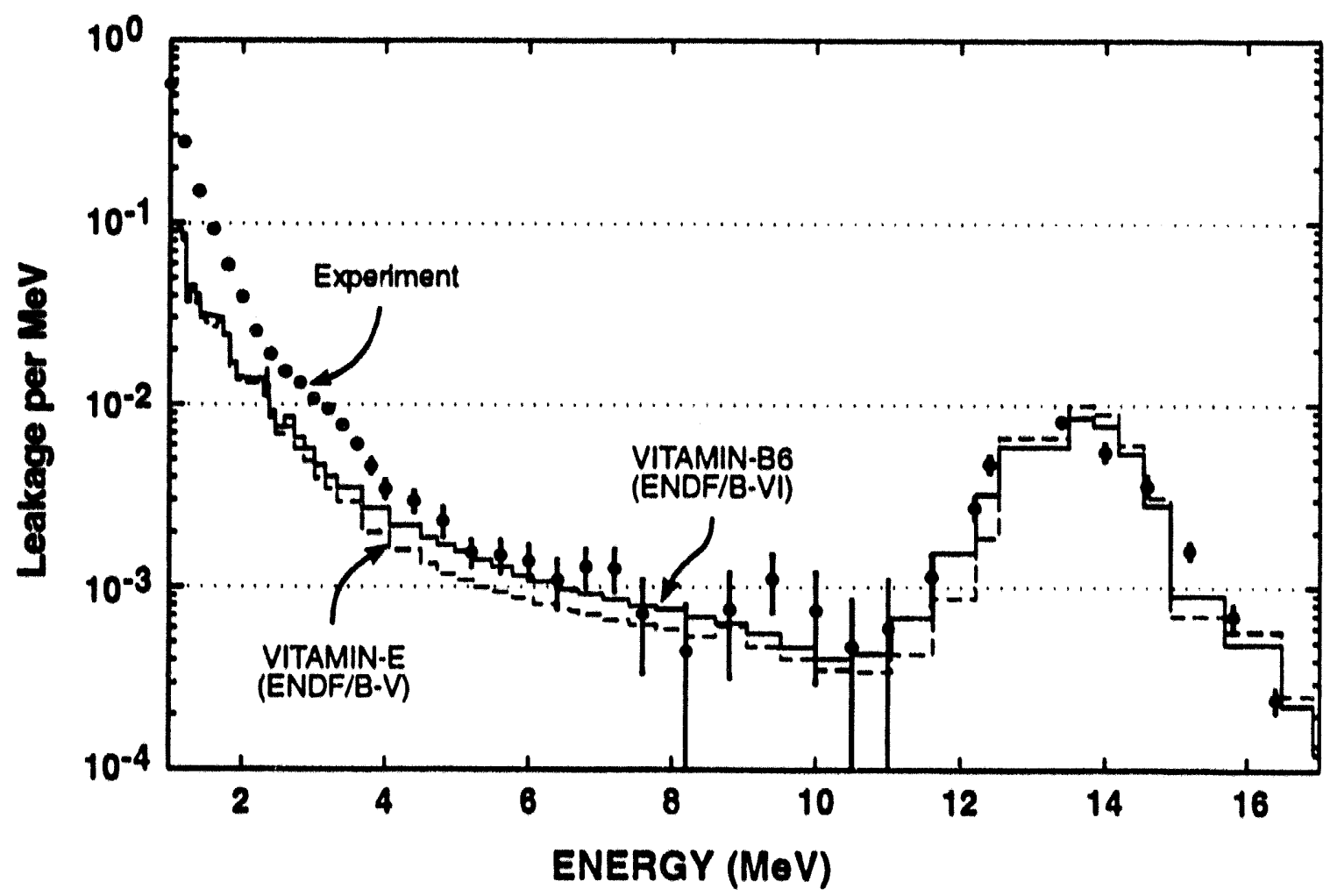

EIGURE 4. Comparison of leakage spectrum from Illinois iron sphere with $D-T$ fusion source at its center. 
(6) "VITAMIN-C: 171 Neutron, 36 Gamma-Ray Group Cross Sections in AMPX and CCCC Interface Formats for Fugion and LMFBR Neutronics," RSIC Data Library Collection, DLC-41 (1978).

(1) "VITAMIN-E: A Coupled 174-Neutron, 38-Gamma-Ray Multigroup Crose-section Library for Deriving Application-Dependent Working Llbrarles for Radiation Traneport Calculations," RSIC Data Library Collection, DLC-113 (1987).

(8) N. M. Greene, et al, "AMPX: A Modular Code syotem for Generating Coupled Multigroup Neutron-Gamma Libraries from ENDF/B," ORNL/TM-3706 (1976).

(2) C. R. Welobln, ot al, "MINX, A Multigroup Interpretation of Nuclear Crose section," LA-6486-MS (1976).

(20) R. E. MacFarlane, D. W. Muir, and R. M. Bolcourt, "The NJOY Nuclear Data Processing syetem, Volume Is User' Manual," LA-9303-M, Vol. I (ENDF-324) (May 1982).

(11) N. M. Greene, W. E. Ford, III, L. M. Patrie, and J. W. Arwood, "AMPX-77: A Modular Code Syetem for Generating Coupled Multigroup Neutron-Gamma Crosa-section LLbraries from ENDF/B-IV and/or ENDE/B-V," ORNL/CSD/TM-283 (October 1992).

(12) J. E. White, R. Q. Wright, R. W. Rousein, and D. T. Ingersoll, "Speciflcation for the Development of BUCLE-93: An ENDE/B-VI Multigroup Crose-section Library for LWR Shielding and Pressure Vessel Dosimetry," ORNL/TM-12230 (November 1992).

(13) "SCALE: A Modular Code syatem for Performing standardized Computer Analyses for Licensing Evaluation," NUREg/CR-200, Revision 4 (ORNL/NUREG/CSD-2/R4), VOlE. I, II, and III (draft Fobruary 1990).

(14) "Cross-section Evaluation Working Group Benchmark specifications," BNL-19302, Volume II (ENDF-202) (November 1974).

(15) N. M. Greene, J. W. Arwood, and C. V. Parks, "The LAW Library - A Multigroup Cross Section Library for Use in Radloactive Waste Analysis Calculations," in Proceedings of International Topical Moeting on safoty Margins in Criticality Safety, November 26-30, 1989, San Francieco, California (1989).

(26) R. H. Johnson, "Integral Tests of Neutron Cross Sections for Iron, Nlobium, Berylilum, and Polyethylene," Ph.D Thesis, Univeraity of Illinole at Urbana-Champaign (1975). 
